\title{
EFEITO DO 2,4-D E DO GLIFOSATE NO CONTROLE DA PARTE AÉREA E DOS RIZOMAS DA LOSNA ${ }^{1}$
}

\author{
ALEXANDRE M. BRIGHENTI ${ }^{2}$, JOSÉ F. DA SILVA ${ }^{\text {s }}$, NEI F. LOPES ${ }^{4}$, ANTONIO A. CARDOSO ${ }^{5}$ \\ A LINO R. FERREIRA ${ }^{6}$
}

RESUMO

\begin{abstract}
A losna (Artemisia verlotorum) é uma planta daninha com alta capacidade de rebrota de seus rizomas e tolerante à maioria dos herbicidas, principalmente os de contato, o que dificulta consideravelmente o seu controle químico e mecânico. O 2,4-D, na dose de 1,662 kg/ha (por interpolação), reduziu o número de plantas vivas de losna de 34 para 6 aos 30 dias após sua aplicação, enquanto que, o glifosate, na dose de $0,856 \mathrm{~kg} / \mathrm{ha}$, reduziu esse número de 27 para 10 . O glifosate, na dose de $0,811 \mathrm{~kg} / \mathrm{ha}$, aos 60 dias após a sua aplicação, reduziu o número de plantas vivas de losna de 34 para 18, enquanto o 2,4-D não mais apresentou efeito. Aos 90
\end{abstract}

dias não foi verificado nenhum efeit o dos dois produtos sobre a losna, em condições de campo. Em casa-de-vegetação verificou-se uma menor capacidade de rebrota dos rizomas com a aplicação do glifosate, enquanto o 2,4-D não mostrou efeito satisfatório. Ocorreu maior redução no peso da matéria secada parte aérea e dos rizomas, quando se aplicou o glifosate nas doses 1,0 e $0,865 \mathrm{~kg} / \mathrm{ha}$, respectivamente. Contudo, o menor valor obtido para aérea foliar da losna foi alcançado quando se aplicou $0,983 \mathrm{~kg} / \mathrm{ha}$ de glifosate.

Palavras -chave: herbicidas sistémicos, plantas daninhas perenes, Artemisia verlotorum.

\section{ABSTRACT \\ Effect of 2,4-D and glyphosate in aerial part and rhizomes of wormwood}

It is difficult to obtain an efficient mechanical and chemical control of wormwood (Artemisia verlotorum) because this weed has a great capacity to sprout and is tolerant to most herbicides. The rate of $1,662 \mathrm{~kg} / \mathrm{ha}$ of $2,4-\mathrm{D}$ reduced the number of living plants from 34 to 6 after 30 days application. However, glyphosate $(0,856 \mathrm{~kg} / \mathrm{ha})$ reduced the number of living plants from 27 to 10 in field conditions. After 60 days application, the number of living plants was reduced from 34 to 18 by $0,811 \mathrm{~kg} / \mathrm{ha}$ of glyphosate. However, no differences were found for application rates of 2,4-D at the same conditions. None of treatments showed satisfac-

\section{INTRODUÇÃO}

Para as comunidades infestantes de ecossistemas agrícolas, sujeitas a frequientes distúrbios promovidos pelo tory performance in relation to wormwood after 90 days application in field conditions. In greenhouse, glyphosate treatments reduced rhizome sprout, though, no differences were found for application rates of 2,4-D. The rates of 1,0 and $0,865 \mathrm{~kg} / \mathrm{ha}$ of glyphosate resulted in lower dry matter weigth of aerial part of the wormwood and its rhizomes, respectively. Leaf area was reduced with glyphosate $(0,983$ $\mathrm{kg} / \mathrm{ha}$ ) at the same conditions.

Additional index words: systemic herbicides, perennial weeds, Artemisia verlotorum.

homem, assumem grande importância a taxa e a eficiência reprodutivas das espécies invasoras, uma vez que, antes de cada distúrbio no local ou mobilização no solo, as plantas já tenham produzido diásporos que lhes asseguram nova colonização (Pitteli, 1985).

1 Recebido para publicação em 16/03/93 e na forma revisada em 11/06/93. Parte da Dissertação de Mestrado do primeiro autor.

$2 \mathrm{Eng}^{\circ} \mathrm{Agr}^{\circ}$, MS c

$3 \mathrm{Eng}^{\circ} \mathrm{Agr}^{\circ}, \mathrm{PhD}$, Dept $^{\circ}$ de Fitotecnia, UFV, 36570-000 Viçosa, MG

$4 \mathrm{Eng}^{\circ} \mathrm{Agr}^{\circ}, \mathrm{PhD}, \mathrm{Dept}^{\circ}$ de Biologia Vegetal, UFV, 36570-000 Viçosa, MG

$5 \mathrm{Eng}^{\circ} \mathrm{Agr}^{\circ}$, DS, Dept ${ }^{\circ}$ de Fitotecnia, UFV, 36570-000 Viçosa, MG

6 Eng $^{\circ} \mathrm{Agr}^{\circ}, \mathrm{MSc}$, Dept $^{\circ}$ de Fitotecnia, UFV, 36570-000 Viçosa, MG 
Neste caso, na competição pela sobrevivência assume importância a capacidade de produção de grande quantidade de propágulos de alta viabilidade, munidos de complexos e diversificados mecanismos de dormência, que lhes asseguram alta longevidade e descontinuidade no processo germinativo. Outros fatores de suma importância na competição pela sobrevivência de plantas invasoras são: efíciente sistema de dispersão, presença de sistemas alternativos de reprodução, alta capacidade fenotípica (Pitteli, 1985).

Plantas daninhas perenes e rizomatosas, como a losna (Artemísia verlotorum Lamotte), são de difícil controle, pois, além das sementes, possuem um caule subterrâneo (rizoma) contendo reserva nutritiva muito elevada, que garante sua perpetuação. Quando esta planta daninha é extirpada, ocorre rebrota muito rápida dos rizomas. Outro problema, aliado a este, é que em regiões onde se pratica agricultura mecanizada, os rizomas são levados pelos implementos agrícolas para outros locais ainda não infestados.

Métodos de controle mecânico, como capinas e uso de cultivadores, não têm mostrado efeito satisfatório no controle desta planta daninha, porque afetam somente a parte aérea, não controlando a massa de rizomas que tem elevada capacidade competitiva com as culturas.

A maioria dos herbicidas são usados no sistema convencional de cultivo, ou seja, após preparo do solo, o que normalmente reduz a sua eficiência sobre a losna. Isto se deve ao fato de que o trabalho do solo, ao invés de controlála, a favorece por fragmentar, dispersar e cobrir suas estruturas vegetativas, diminuindo o contato das mesmas com os herbicidas aplicados.

O objetivo deste trabalho foi avaliar o efeito de herbicidas sobre a planta de losna, visando a controlar suas estruturas vegetativas.

\section{MATERIAL E MÉTODOS}

Este experimento foi conduzido em Venda Nova do Imigrante (ES), situada a uma latitude $20^{\circ} 20^{\prime} \mathrm{S}$ e longitude $41^{\circ} 12^{\prime} \mathrm{W}$, durante o período de 5 de abril a 15 de julho de 1991.0 solo apresentava as seguintes características: textura franco-argilo-arenosa com $27 \%$ de areia grossa, $17 \%$ de areia fina, $23 \%$ de silte, $33 \%$ de argila, $2,8 \%$ de matéria orgânica e pH 6,6.

Foram utilizados 16 tratamentos provenientes da combinação de 4 doses $(0,0,0,384,0,768$ e $1,152 \mathrm{~kg} / \mathrm{ha})$ do ingrediente ativo do herbicida glifosate (Roundup) e 4 doses $(0,0,0,576,1,152$ e $1,728 \mathrm{~kg} / \mathrm{ha})$ do ingrediente ativo do herbicida 2,4-D (U-46 D Fluid), num delineamento inteiramente casualizado, em arranjo fatorial $4 \times 4$ com 4 repetições.

A aplicação dos herbicidas foi feita com um pulverizador costal manual, com capacidade para 20 litros, calibrado a uma pressão aproximada de $206,8 \mathrm{kPa}$, dando uma vazão de 2501/ha, quando a losna tinha aproximadamente 20 $\mathrm{cm}$ de altura.

Avaliou-se a ação dos produtos sobre a losna determinando-se o número de plantas vivas aos 30, 60 e 90 dias após a aplicação dos herbicidas (DAAH). As amostragens foram realizadas em área de $0,25 \mathrm{~m}^{2}$, situadas nas regiões centrais das parcelas.
Para avaliar a eficiência dos herbicidas no controle dos rizomas da losna, foi instalado um experimento em casa-devegetação, retirando-se amostras de rizomas de todos os tratamentos do experimento de campo, aos 30 dias após a aplicação dos herbicidas.

Quatro fragmentos de rizomas, de $40 \mathrm{~mm}$ de comprimento, foram plantados em vasos de 3 litros de capacidade, contendo $3 \mathrm{~kg}$ de material de solo argilo-arenoso, com $32 \%$ de areia grossa, $13 \%$ de areia fina, $14 \%$ de silte, $41 \%$ de argila, $4 \%$ de matéria orgânica e $\mathrm{pH} 5,3$, e mantidos em casa-de-vegetação. $\mathrm{O}$ delineamento experimental foi o inteiramente casualizado com 4 repetições.

Os vasos foram irrigados dia riamente, mantendo-se um nível de água próximo da capacidade de campo. Foram feitas duas adubações, em intervalos de 12 dias, com $100 \mathrm{ml}$ por vaso de uma solução, contendo 20 gramas da formulação composta 15-15-20 (N total 15\%, $\mathrm{K}_{2} 020 \%$, Ca 1,1\%, S 4\%,

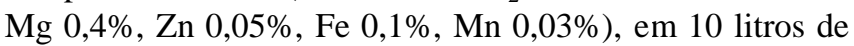
água.

Aos 30 dias após o plantio dos rizomas, as plantas foram cortadas rente ao solo e seus rizomas lavados em água corrente para retirar as partículas de solo. A área foliar foi determinada através de um medidor Delta T Devices e o peso da matéria seca da parte aérea e dos rizomas foi obtido por meio de uma balança de precisão, após secagem do material em estufa de ventilação forçada por $48 \mathrm{~h}$ a $75^{\circ} \mathrm{C}$.

\section{RESULTADOS E DISCUSSÃO}

A maior eficiência de controle da losna ocorreu com o emprego de ambos os produtos, aos 30 dias após a aplicação. Não foi verificado o efeito da interação dos herbicidas neste mesmo período. A redução do número de plantas vivas foi calculada a partir das equações de regressão. Houve uma redução de 34 para 6 plantas com a dose de 1,662 kg/ha de 2,4-D (Figura 1A). Entretanto, o glifosate, na dose de 0,856 $\mathrm{kg} / \mathrm{ha}$, reduziu esse número de 27 para 10 plantas vivas (Figura 1B).

O glifosate, na dose de $0,811 \mathrm{~kg} / \mathrm{ha}$, reduziu o número de plantas vivas de 34 para 18, aos 60 dias após sua aplicação (Figura 2). Não foi verificado efeito significativo de nenhuma das doses do 2,4-D nesse mesmo período. Aos 90 DAA, não foi obtido controle eficiente da losna, porque, possivelmente, grande parte do 2,4-D tenha sido metabolizado pela planta daninha. Fites et al. (1964) e Lingle \& Suttle (1985) verificaram resultados semelhantes, trabalhando com outras espécies. Também com o glifosate, não se verificou efeito aos 90 dias após a aplicação, provavelmente em função de as condições climáticas da região terem favorecido a recuperação da losna.

Com relação ao experimento de casa-de-vegetação, houve uma maior redução no peso da matéria seca da parte aérea dos rizomas, bem como da área foliar, com a aplicação do herbicida glifosate. Entretanto, não foi verificado efeito significativo em nenhuma das doses do 2,4-D. A dose de glifosate que proporcionou menor peso da matéria seca da parte aérea foi $1,0 \mathrm{~kg} / \mathrm{ha}$. Com relação ao menor peso da matéria seca dos rizomas, a dose $0,865 \mathrm{~kg} / \mathrm{ha}$ foi a mais eficiente. As matérias secas da parte aérea e dos rizomas 


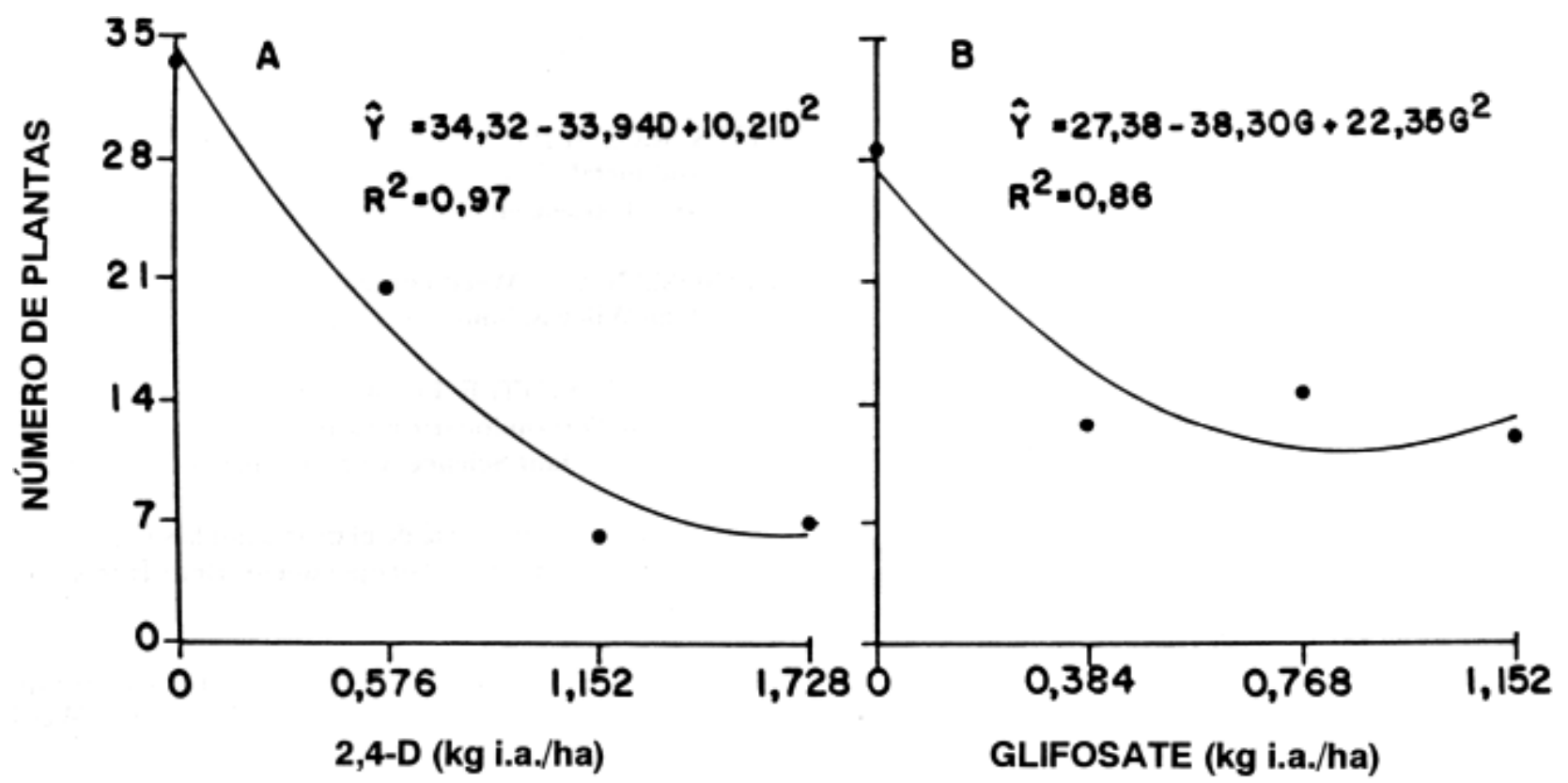

FIG. 1 - Número de planas vivas de losna aos 30 dias após a aplicação de 2,4-D (A) e de glifosate (B).

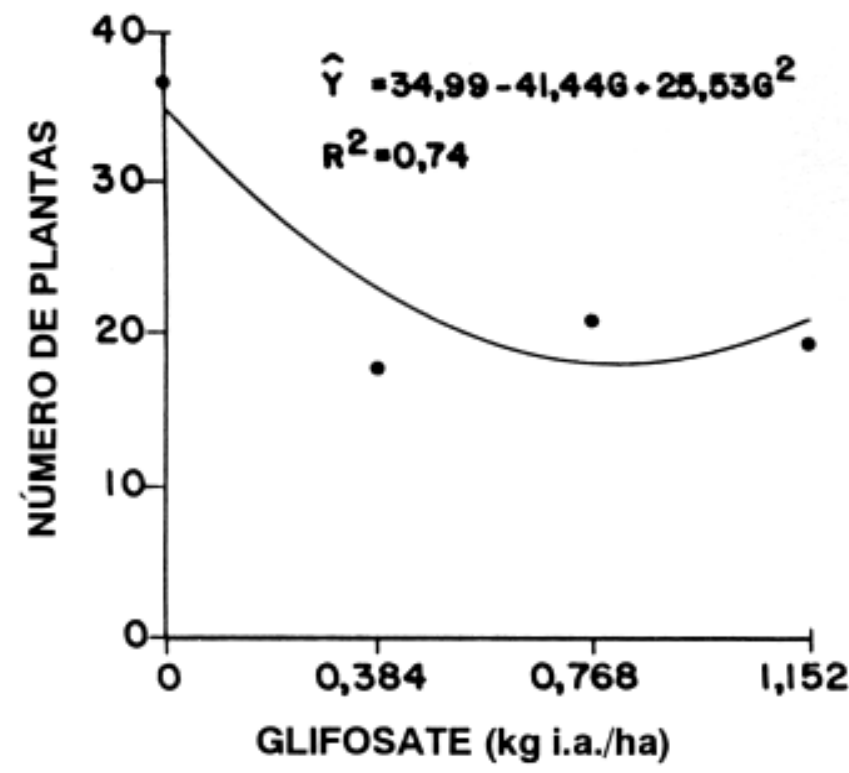

FIG. 2 - Número de planas vivas de losna aos 60 dias após a aplicaçáo de glifosate.

foram calculadas a partir das equações de regressão (Figuras 3A e 3B, respectivamente). Entretanto, o menor valor obtido com relação à área foliar ocorreu quando se aplicou 0,983 $\mathrm{kg} / \mathrm{ha}$ de glifosate (Figura 4).

Concentrações mais elevadas do glifosate mostraram incremento com relação às características observadas, pois doses altas do produto causaram danos aos elementos de tubo crivado do floema, dificultando a translocação e, comeqüentemente, reduzindo o efeito do produto (Kling man, 1961; Spranlde et al., 1975).
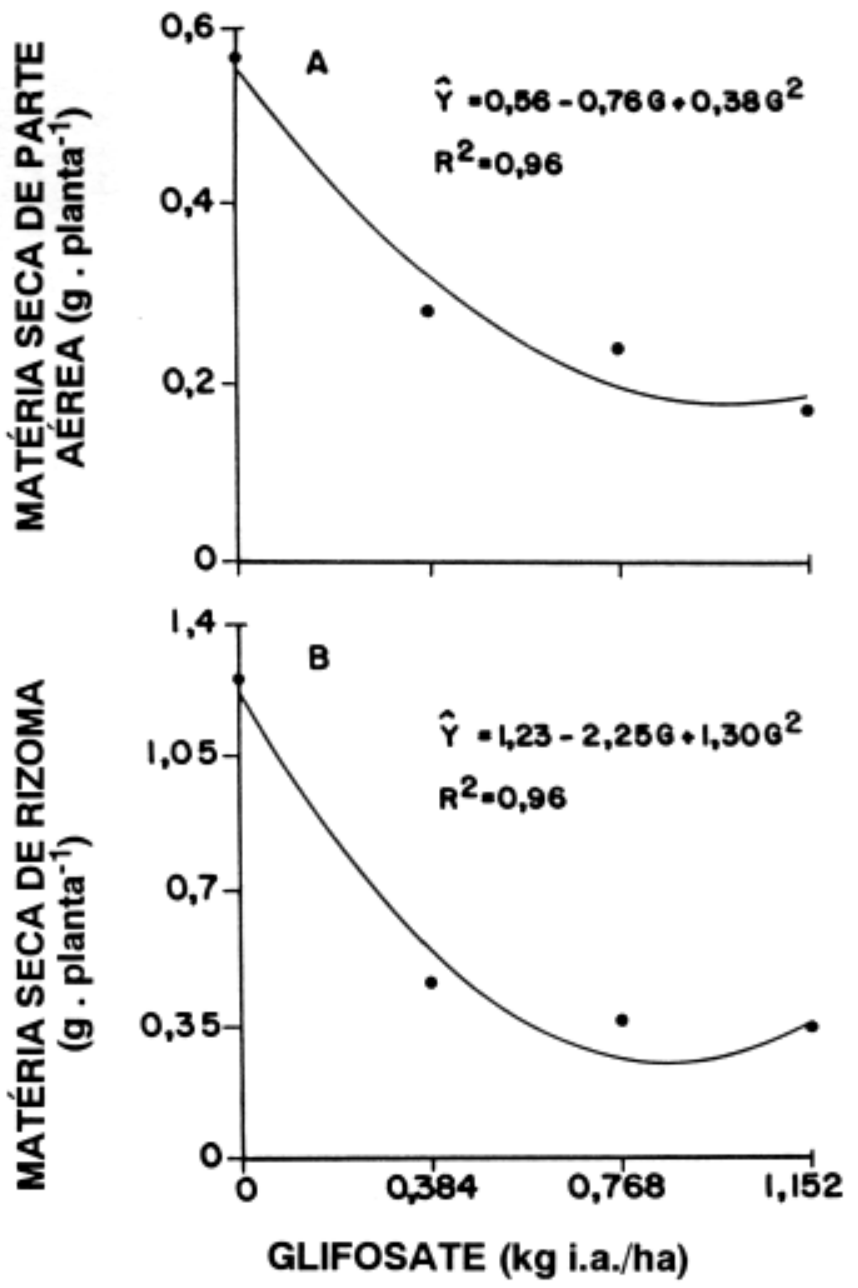

FIG. 3 - Peso da matéria seca da parte aérea (A) e dos rizomas (B) de losna após a aplicação de glifosate. 


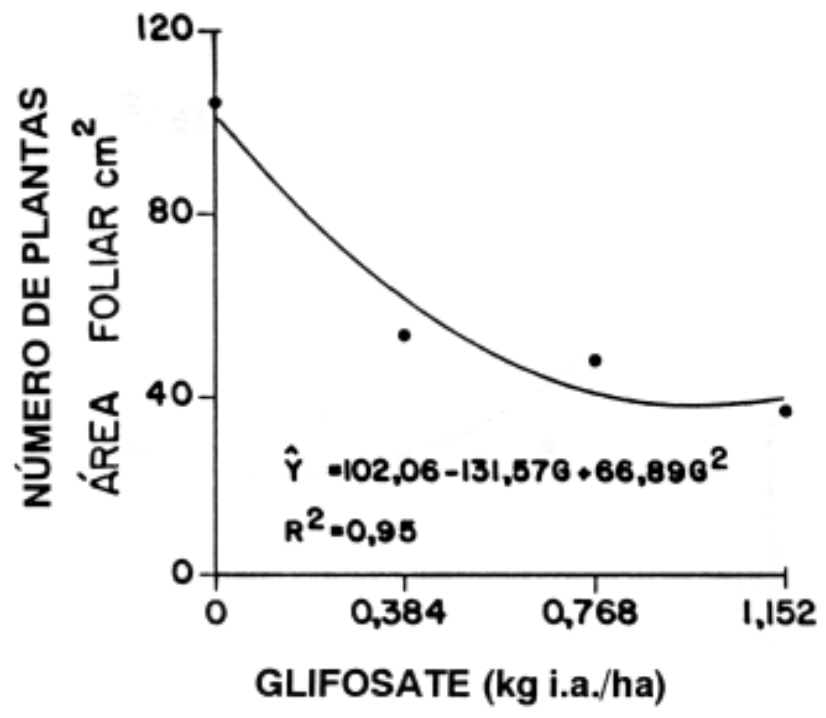

FIG. 4 - Área foliar de losna após a aplicação de glifosate.

\section{LITERATURA CITADA}

FITES, R.C.; SLIFE, F.W.; HANSON, J.B. Tran slocation and metabolism of radioative 2,4-D in jímsonweed. Weed Research, v.12, n.3, p.180-183, 1964.

KLINGMAN, G.C. Weed control: as a science. New York: John Wiley \& Sons, 1961. 421p.

LINGLE, E.S.; SUTTLE, J.C. A model system for the study of 2,4-D translocation in leafy spurge. Canadian Journal Plant Science, v.65, n.2, p.369-317, 1985.

PI TTELI, R.A. Interferência de plantas daninhas em culturas agrícolas. Infor me Agropecuário, Belo Horizonte, v.11, n.129, p.16-27, 1985.

SPRANKLE， P.; MEGGITT, W.F.; PENNER D. Absorption, action and tranlocation of glyphosate. Weed Science, v.23, n.3, p.235-240, 1975. 